\title{
NOVEL TRANSETHOSOME CONTAINING GREEN TEA (CAMELLIA SINENSIS L. KUNTZE) LEAF EXTRACT FOR ENHANCED SKIN DELIVERY OF EPIGALLOCATECHIN GALLATE: FORMULATION AND IN VITRO PENETRATION TEST
}

\author{
EFFIONORA ANWAR*, DELLY RAMADON, GHINA DESVIYANTI ARDI \\ Department of Pharmaceutical Technology, Faculty of Pharmacy, Universitas Indonesia, Depok, 16424, Indonesia. \\ Email: effionora.anwar@farmasi.ui.ac.id
}

Received: 20 June 2018, Revised and Accepted: 19 November 2018

\section{ABSTRACT}

Objective: This study aimed to formulate a transethosome cream (TEC) to increase skin penetration of epigallocatechin gallate (EGCG) in green tea leaf extract and evaluate their physicochemical characteristics and skin penetration capacity.

Methods:Transethosomeswerepreparedthroughthin-layerhydrationmethodinthreeformulations(F1-F3)withdifferentSpan80andethanolconcentrations. Transethosomemorphologywascharacterized usingtransmissionelectronmicroscopy,particlesize, polydispersity(PDI), andzetapotential usingaparticle size analyzer and entrapment efficiency (EE). Penetration was tested using an in vitro Franz diffusion cell with female Sprague-Dawley rat skin as the membrane.

Results: Transethosome F2 containing green tea extract equivalent to 3\% EGCG, 4\% Lipoid P30, 0.75\% Span 80, and 30\% ethanol had the best characteristic including spherical shape, smallest particle size $(35.35 \mathrm{~nm}), 0.319 \mathrm{PDI}$, zeta potential of $-29.97 \pm 3.05 \mathrm{mV}$, and highest EE of $45.26 \% \pm 8.15 \%$. TEC permitted greater flux than non-TEC (first phase: $60.56 \pm 4.52$ vs. $25.69 \pm 0.83 \mu \mathrm{g}^{\circ} \mathrm{cm}^{-2} \bullet \mathrm{h}^{-1}$ and second phase: $23.13 \pm 1.38$ vs. $\left.7.36 \pm 1.59 \mu \mathrm{g} \bullet \mathrm{cm}^{-2} \bullet \mathrm{h}^{-1}\right)$.

Conclusion: Transethosome can increase the skin penetration of green tea leaf extract.

Keywords: Cream, Epigallocatechin gallate, Green tea leaf extract, Penetration, Transethosome.

(c) 2018 The Authors. Published by Innovare Academic Sciences Pvt Ltd. This is an open access article under the CC BY license (http://creativecommons. org/licenses/by/4. 0/) DOI: http://dx.doi.org/10.22159/ijap.2018.v10s1.66

\section{INTRODUCTION}

Green tea from the tea plant Camellia sinensis has several health benefits [1]. Bioactive compounds present in green tea leaves include alkaloids, flavonoids, and phenols [2]. The flavonoids (particularly the catechin fraction) are basic phenolic compounds responsible for antioxidant activity [3]. Epigallocatechin gallate (EGCG) is the major catechin in green tea and the primary source of its antioxidant activity [4]. EGCG is hydrophilic ( $\log \mathrm{p}=0.48)$ [5] and thus has poor skin permeability. However, skin delivery has several advantages such as the mitigation of gastrointestinal disturbances and bypass of hepatic firstpass metabolism [6]. Therefore, a delivery system that can facilitate the skin absorption of EGCG is desirable, and a formulation using transethosomes could be among the best such vehicles for EGCG-based treatment.

For the skin delivery of such compounds, several strategies have been used to bypass the stratum corneum barrier. Liposomes have been used for topical drug delivery; however, conventional liposomes do not deeply penetrate the skin [7]. To overcome this limitation, novel lipid vesicles - transethosome and transfer some - were developed. Transethosome is a modified ethosome formed into lipid vesicles that can improve penetration through the skin [8]. Transethosome contains high ethanol content together with an edge activator or permeation enhancer [7]. Transethosome can be formulated into a semi-solid form such as a cream. Creams generally have greater esthetic appeal because they are non-greasy and can be easily applied, spread, and removed [9].

In this study, transethosomes containing green tea extract were formulated into a cream (transethosome cream, TEC) and evaluated for their physicochemical characteristics and skin penetration capacity.
This formulation exhibited highly advantageous physicochemical characteristics, high entrapment efficiency (EE), and markedly enhanced skin flux than a non-TEC (NTEC).

\section{METHODS}

Materials

Green tea leaf extract (C. sinensis L. Kuntze) (Andy Biotech [Xi'an] Co. Ltd., China), EGCG standard (Sigma-Aldrich, Singapore), Lipoid P30 (Lipoid $\mathrm{GmbH}$, Germany), solvents, and other chemical reagents were of analytical grade.

\section{EGCG assay of green tea leaf extract}

Green tea left extract was prepared according to the methods of Fangueiro et al. with some modifications [10]. Standard solutions of EGCG were prepared at $25,30,35,40,45$, and $50 \mu \mathrm{g} / \mathrm{mL}$ for constructing a calibration curve. The solution was analyzed using reversed-phasehigh-performance liquid chromatography with a UV-visible detector set at $280 \mathrm{~nm}$ and a flow rate of $1.0 \mathrm{~mL} / \mathrm{min}$. The mobile phase comprised $0.05 \%(\mathrm{v} / \mathrm{v})$ acetic acid: acetonitrile $(87: 13 \mathrm{v} / \mathrm{v}, \mathrm{pH}$ approximately 4.0). The injection volume was $20 \mu \mathrm{g} / \mathrm{mL}$, and retention time was approximately $16 \mathrm{~min}$.

\section{Antioxidant activity of green tea leaf extract}

The antioxidant activity was measured according to the method of Mishra et al [11]. Ascorbic acid standard and green tea leaf extract solutions were prepared at different concentrations. DPPH $100 \mu \mathrm{g} / \mathrm{mL}$ $(1.0 \mathrm{~mL})$ and methanol $(2.0 \mathrm{~mL})$ were added to $1.0 \mathrm{~mL}$ of each sample solution. The mixture was shaken and incubated at room temperature for $30 \mathrm{~min}$. The antioxidant activity was determined using a UV-visible spectrophotometer at $514 \mathrm{~nm}$. 


\section{Transethosome formulation}

Transethosome was prepared in three formulations (Table 1) through the thin-layer hydration method. Lipoid P30 and Span 80 were dissolved in dichloromethane in a round-bottom flask and the dichloromethane was removed by rotary evaporation at $40^{\circ} \mathrm{C}$. Nitrogen gas was applied to form a thin layer that was stored in the refrigerator for $24 \mathrm{~h}$, rehydrated using a solvent containing green tea leaf extract in 95\% ethanol and phosphate buffer ( $\mathrm{pH} 5.5$ ), and then shaken by rotation for $1 \mathrm{~h}$ at $37^{\circ} \mathrm{C}$. All products were stored at $4^{\circ} \mathrm{C}$ in the refrigerator until testing.

Transethosome morphology was examined using transmission electron microscopy (TEM) (FEI type Tecnai G2 20 S-TWIN). All samples were analyzed with an accelerating voltage of $200 \mathrm{kV}$ at $20^{\circ} \mathrm{C}$ and using $\mathrm{LaB}_{6}$ filament as the electron source. Briefly, the suspension was aliquoted onto a carbon-coated copper grid and dried at room temperature for imaging at various magnifications (Fig. 1).

The particle size distribution, PDI, and zeta potential were determined through dynamic light scattering using a particle size analyzer (Malvern Zetasizer). The three formulations were added to $10 \mathrm{~mL}$ of distilled water and measured in triplicate.

EE was measured through the indirect method. Drug content was measured first in the transethosome preparation using HPLC and then in the supernatant after the separation of the transethosome component using centrifugation. Briefly, $0.5 \mathrm{~mL}$ of the transethosome suspension was added to $1.0 \mathrm{~mL}$ of phosphate buffer ( $\mathrm{pH} 5.5$ ), and the mixture centrifuged at 14,000 rpm 4 times for $30 \mathrm{~min}$ each. The precipitate was discarded, and the supernatant was collected and mixed with phosphate buffer ( $\mathrm{pH}$ 5.5) and ethanol. The percentage EE of EGCG was calculated by dividing (Qt-Qs) with Qt, then times 100\%, where $\mathrm{Qt}$ is the concentration of EGCG in transethosome suspension $(\mu \mathrm{g} / \mathrm{mL})$ and $\mathrm{Qs}$ is the concentration of EGCG in the supernatant $(\mu \mathrm{g} / \mathrm{mL})$. Based on predetermined criteria, the suspension with the most optimum concentration was chosen as the ingredient for the preparation of the cream. Table 2 presents the formulas for TEC and NTEC.

The cream was prepared by separately heating an oil mixture (stearic acid, cetyl alcohol, isopropyl myristate, dimethicone, and BHT) and an aqueous mixture (TEA, propylene glycol, sodium sulfite anhydrous, and distilled water) in a water bath at $70^{\circ} \mathrm{C}$. The oil phase was then added to the aqueous phase and mixed using a homogenizer at 500-1000 rpm. Then, active ingredients were added to the cream base $(1 \%, v / v)$ and homogenized. The cream was then evaluated for its organoleptic properties, $\mathrm{pH}$, homogeneity, viscosity, rheological properties, and in vitro skin penetration capacity using a Franz diffusion cell test. This latter study was approved by the Ethics Committee of Cipto Mangunkusumo Hospital, Faculty of Medicine, Universitas Indonesia, Number. 313/UN2.F1/ETIK/2017. Abdominal skin from female Sprague-Dawley rats (2-3 months old, $200 \mathrm{~g}$ ) was used as the test membrane. The surface area of membrane was $2.0096 \mathrm{~cm}^{2}$. The receptor had a compartment volume of $15 \mathrm{~mL}$ filled with phosphate buffer (pH 5.5) at $37^{\circ} \mathrm{C}$

For flux analysis, $1 \mathrm{~g}$ of the cream was applied to the membrane and $3.0 \mathrm{~mL}$ aliquots were obtained from the receptor compartment after 10 , $30,60,120,180,240,360,480,600,720,840,960,1080,1200,1320$, and $1440 \mathrm{~min}$. The removed volume was replenished with an equal volume of the receptor media. The amount of EGCG in the receptor sample was determined using HPLC. This in vitro penetration test was conducted in triplicate for all samples.

\section{RESULTS AND DISCUSSION}

Antioxidant activities of plant extracts are mainly contributed by polyphenols [12-16]. Green tea contains phenolic compounds that act as powerful chain-breaking antioxidants, which might directly contribute to antioxidant activity. Indeed, there are strong correlations between antioxidant activity and the total phenolic and flavonoid contents

Table 1: Transethosome formulas

\begin{tabular}{llll}
\hline Material & \multicolumn{3}{l}{ Concentration (\%) } \\
\cline { 2 - 4 } & F1 & F2 & F3 \\
\hline Green tea leaf extract equal to EGCG & 3.0 & 3.0 & 3.0 \\
Lipoid P30 & 4.0 & 4.0 & 4.0 \\
Span 80 & 0.5 & 0.75 & 0.5 \\
Ethanol 95\% & 30 & 30 & 35 \\
Phosphate buffer pH 5.5 & ad 100 & ad 100 & ad 100 \\
\hline
\end{tabular}

EGCG: Epigallocatechin gallate

Table 2: Cream formulas

\begin{tabular}{lll}
\hline Material & \multicolumn{2}{l}{ Concentration (\%) } \\
\cline { 2 - 3 } & TEC & NTEC \\
\hline Transethosome/green tealeaf extract (EGCG content) & 1.0 & - \\
Green tea leaf extract (EGCG content) & - & 1.0 \\
Stearic acid & 10.0 & 10.0 \\
Cetyl alcohol & 2.3 & 2.3 \\
Isopropyl myristate & 3.05 & 3.05 \\
TEA & 2.0 & 2.0 \\
Propylene glycol & 10.0 & 10.0 \\
Sodium sulfite anhydrous & 0.1 & 0.1 \\
BHT & 0.1 & 0.1 \\
Dimethicone & 10.0 & 10.0 \\
Distilled water & Ad 100 & Ad 100 \\
\hline
\end{tabular}

TEC: Transethosome cream, NTEC: Non-transethosome cream,

EGCG: Epigallocatechin gallate
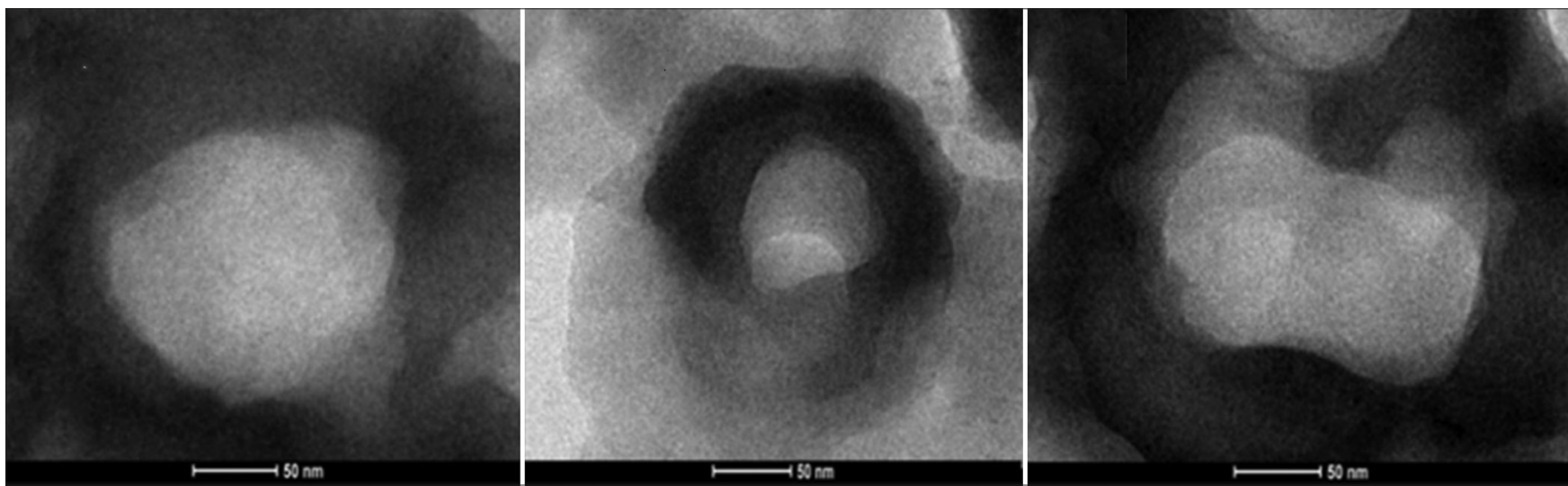

Fig. 1: Morphology of transethosome green tea extract 
Table 3: Physicochemical characteristics of the three transethosome green tea extract formulations

\begin{tabular}{lllll}
\hline Formulation code & Morphology & Particle size (nm) & PDI & Zeta potential (mV) \\
\hline F1 & Irregular spherical & 46.24 & 0.165 & $-32.73 \pm 4.25$ \\
F2 & Irregular spherical & 35.35 & 0.319 & $-29.97 \pm 3.05$ \\
F3 & Irregular spherical & 632.0 & 0.449 & $-47.77 \pm 4.93$ \\
\hline
\end{tabular}

PDI: Polydispersity index, EE: Entrapment efficiency

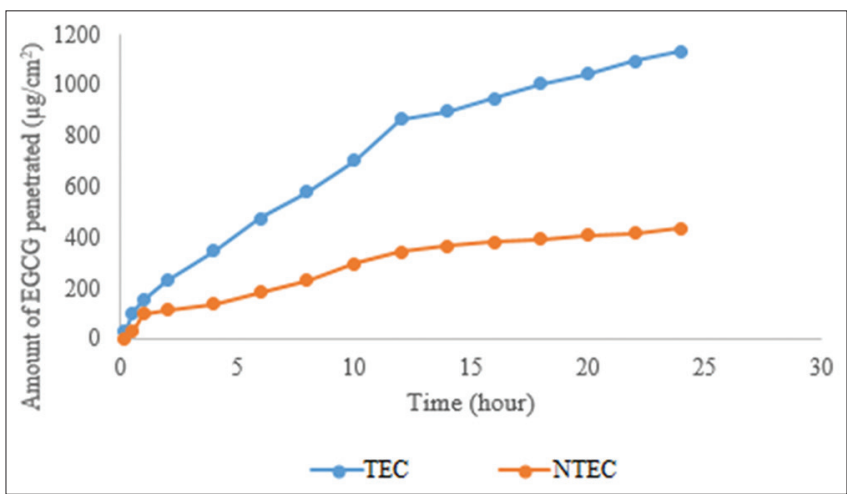

Fig. 2: Cumulative amount of epigallocatechin gallate penetrated

of $C$. sinensis. In this study, the EGCG content of green tea leaf extract was $53.66 \% \pm 0.35 \%$, and the antioxidant $\mathrm{IC}_{50}$ value was $1.38 \mu \mathrm{g} / \mathrm{mL}$, which was substantially lower than that of ascorbic acid $(2.71 \mu \mathrm{g} / \mathrm{mL})$, indicating a stronger antioxidant activity.

Transethosome containing green tea leaf extract was prepared in three formulations using Lipoid P30, Span 80, ethanol 95\%, and phosphate buffer ( $\mathrm{pH}$ 5.5). Transethosome contained ethanol together with an edge activator or permeation enhancer, which was expected to improve permeation [7]. Morphological analysis through TEM revealed that transethosome particles were irregular spheres (Fig. 1). This conformation may be due to rearrangement in the lipid bilayer of vesicles due to the combination of ethanol and edge activator [8].

Results of physicochemical characterization are summarized in Table 3. The rank order $\mathrm{Z}$-average values of the transethosome formulas were $\mathrm{F} 2<\mathrm{F} 1<\mathrm{F} 3$. Formula $\mathrm{F} 2$ with the highest surfactant concentration (lower surface tension) had the smallest mean particles size, in accordance with the findings of previous studies [13]. A PDI of $<0.5$ indicates that transethosome vesicles are homogenous; therefore, based on the criteria of particle size and homogeneity using Malvern particle size analyzer, all three formulations satisfy public standards. Zeta potential is an important physical parameter for the prediction of vesicle stability. All transethosome formulations exhibited a negative zeta potential due to the charge transition of vesicles induced by ethanol [17]. All three formulations also exhibited reasonable entrapment efficiencies, with F2 exhibiting the highest efficiency $(45.26 \% \pm 8.15 \%)$. Thus, higher surfactant (Span 80$)$ concentration was associated with greater EE, in accordance with Srivastava et al. [6]. Based on physicochemical characterization, transethosome formula F2 with the smallest particle size, PDI $<0.5$, good zeta potential, and the highest EE was chosen as the active ingredient for the cream formulation.

Both TEC and NTEC were pale yellow (Pantone $9120 \mathrm{U}$ ), had the aroma of tea, and exhibited similar pH values $(5.63 \pm 0.02$ and $5.34 \pm 0.02$, respectively). TEC had a higher viscosity than NTEC as measured at $20 \mathrm{rpm}$ (12400 vs. $12000 \mathrm{cps}$ ), which was likely due to the presence of phospholipid, surfactant, and ethanol. Both creams had similar rheology properties (thixotropic plastic). However, TEC exhibited a substantially greater delivery capacity for EGCG into rat skin (cumulative amount: $1133.90 \pm 48.15$ vs. $436.26 \pm 28.52 \mu \mathrm{g} / \mathrm{cm}^{2}$; first phase flux: $60.56 \pm 4.52$ vs. $25.69 \pm 0.83 \mu \mathrm{g} \bullet \mathrm{cm}^{-2} \bullet \mathrm{h}^{-1}$ and second phase: $23.13 \pm 1.38$ vs. $7.36 \pm 1.59 \mu \mathrm{g} \bullet \mathrm{cm}^{-2} \bullet \mathrm{h}^{-1}$ ) (Fig. 2)

Based on Fig. 2, TEC promotes greater EGCG penetration into rat skin than NTEC. The superior delivery capacity of transethosome appears to reflect a synergism among ethanol, surfactant, vesicle, and skin lipids [8].

\section{CONCLUSION}

TEC facilitated a superior skin penetration of EGCG than NTEC. Thus, this formulation may prove effective for topical antioxidant treatment or an efficient systemic delivery.

\section{ACKNOWLEDGMENTS}

The authors are highly thankful to Universitas Indonesia and Ministry of Research and Technology for the financial support through Grant Research (PUDPT) 2018.

\section{CONFLICTS OF INTEREST}

The authors declare that there are no conflicts of interest in this study.

\section{REFERENCES}

1. Anand J, Upadhyaya B, Rawat P, Rai N. Biochemical characterization and pharmacognostic evaluation of purified catechins in green tea (Camellia sinensis) cultivars of India. Biotechnology 2015;5:285-94.

2. Lister E, Wilson P. Measurement of Total Phenolics and Abts Assay for Antioxidant Activity Crop Lincoln. New Zealand: Research Institute; 2001.

3. Horzic D, Komes D, Belscak A, Ganic KK, Ivekovic D, Karlovic D. The composition of polyphenols and methylxanthine in teas and herbal infusions. Food Chem 2009;115:441-8.

4. Fujimura Y, Tachibana H, Maeda-Yamamoto M, Miyase T, Sano M, Yamada K. Antiallergic tea catechin, (-)-epigallocatechin-3-O-(3O-methyl)-gallate, suppresses Fc-epsilon RI expression in human basophilic KU812 cells. J Agric Food Chem 2002;50:5729-34.

5. Patel AR, Velikov KP. Non-covalent interactions of green tea polyphenols: Source of novel colloidal structures. Nova Biomed 2013;2013:151-66.

6. Srivastava S, Maurya A, Gupta P. A review article on transdermal drug delivery system. World J Pharm Pharm Sci 2016;5:1702-25.

7. Song CK, Balakrishnan P, Shim CK, Chung SJ, Chong S, Kim DD, et al. A novel vesicular carrier, transethosome, for enhanced skin delivery of voriconazole: Characterization and in vitro/in vivo evaluation. Colloids Surf B Biointerfaces 2012;92:299-304.

8. Ascenso A, Raposo S, Batista C, Cardoso P, Mendes T, Praça FG, et al. Development, characterization, and skin delivery studies of related ultradeformable vesicles: Transfersomes, ethosomes, and transethosomes. Int J Nanomedicine 2015;10:5837-51.

9. Allen LV, Popovich NG, Ansel HC. Ansel's Pharmaceutical Dosage Forms and Drug Delivery Systems. $9^{\text {th }}$ ed. Philadelphia, PA: Lippincott Williams and Wilkins; 2011

10. Fangueiro JF, Parra A, Silva AM, Egea MA, Souto EB, Garcia ML, et al. Validation of a high performance liquid chromatography method for the stabilization of epigallocatechin gallate. Int J Pharm 2014;475:181-90.

11. Mishra K, Ojha H, Chaudhury NK. Estimation of antiradical properties of antioxidants using DPPH assay: A critical review and results. Food Chem 2012;130:1036-43.

12. Izzreen MN, Fadzelly AB. Phytochemicals and antioxidant properties of different parts of Camellia sinensis leaves from Sabah tea plantation in Sabah, Malaysia. Int Food Res J 2013;20:307-12

13. Zirak MB, Pezeshki A. Effect of surfactant concentration on the particle size, stability and potential zeta of beta carotene nano lipid carrier. Int $\mathrm{J}$ Curr Microbiol App Sci 2015;4:924-32. 
14. Geetha S, Irulandi K, Mehalingam P. Evaluation of antioxidant and free radical scavenging activities of different solvent extracts of leaves of Piper umbellatum. Asian J Pharm Clin Res 2017;10:274-6.

15. Farhan H. Studying the cytotoxic and antioxidant activities of crude extracts from Anacyclus ngellifolius boss grown in North Lebanon. Asian J Pharm Clin Res 2018;11:376-80.
16. Srinivasan P, Jayagopal M, Ramachandran J. Evaluation of in-vitro antioxidant and fibrinolytic activity of flavonoid-rich fraction from the whole plant of Wedelia chinensis. Asian J Pharm Clin Res 2016;9:234-9.

17. Touitou E, Dyan N, Bergelson L, Godin B, Eliaz M. Ethosomes-novel vesicular carriers for enhanced delivery: Characterization and skin penetration properties. J Control Release 2000;65:403-418 